\title{
Sobre o ataque de convulsões generalizadas produzido pelo reaquecimento brusco de animais préviamente resfriados
}

\author{
por \\ Miguel Ozorio de Almeida, Tito Cavalcanti e M. Vianna Dias
}

Em trabalho anterior, dois dentre nós, em colaboração com $\mathrm{H}$. Moussatché, ${ }^{1}$ descreveram um violento ataque convulsivo que se provoca nas Rãs sul-americanas (Leptodactylus ocellatus) quando, após permanecerem 20 a 30 minutos em um banho a temperatura próxima de $0^{\circ} \mathrm{C}$., são bruscamente mergulhadas em um banho a temperatura acima de $30^{\circ} \mathrm{C}$.

Tal ataque, que se produz na quasi totalidade dos animais experimentados, depende essencialmente da mudança brusca de temperatura dos centros nervosos. De fato, uma vez terminado o acesso convulsivo, verifica-se que a temperatura central do animal se encontra nas visinhanças de $20^{\circ} \mathrm{C}$., não tendo havido tempo para que o corpo tome a temperatura do banho quente. Êle não se produz se o sistema nervoso central é destruído e também não se mostra nas regiões correspondentes a partes dos centros nervosos lesados. Conquanto as excitações exteriores possam sôbre êle ter influência, não deixa de se produzir após a secção das raízes posteriores, ou a ablação da pele ou ainda a destruição dos labirintos.

Instruídos pela experiência adquirida nas pesquisas sôbre a crioepilepsia, na qual foi verificado que a espécie animal, assim como as condições de vida (clima, temperatura, etc.) têm influência acentuada, resolvemos fazer um estudo sistemático do ataque pelo reaquecimento em outras espécies animais. Conquanto os nossos trabalhos não estejam ainda terminados, damos aqui um resumo dos primeiros resultados.

Em nossas experiências atuais empregamos exemplares de sapos (Bufo crucifer) e de duas espécies de Lacertilios (Tropidurus torquatus e Tupinambis teguichin).

\footnotetext{
* Entregue para publicação em 16 de Maio de 1950, com 1 figura.

1 Ozorio de Almeida, H. Moussatché et M. Vianna Dias. - Sur une attaque de convulsions généralisées produite par la réchauffement brusque des Grenouilles préalablement réfroidies. Rev. Bras. Biol. 1945, V, 125-131.
} 
E' preciso desde logo notar que o tempo de estar na água fria, assim como a temperatura que deve ter o banho quente são diferentes conforme as espécies e devem apresentar também diferenças apreciáveis de um para outro indivíduo. A determinação exata das condições de produção do ataque representa, pois, um trabalho prévio que não poude ainda ser terminado.

A técnica seguida nas experiências atuais é precisamente a mesma já empregada nas experiências com as rãs. Apenas há a notar a necessidade de empregar frascos, tanto para o resfriamento como para 0 reaquecimento, muito maiores do que os anteriormente utilisados, quando se lida com animais de dimensões muito maiores do que as de rã, como é o caso dos grandes lagartos Tupinambis teguixin.

\section{RESULTADOS}

I. Sapos. Os sapos dão ataques muito aproximadamente nas mesmas condições que as rãs. Sete animais foram experimentados; todos ficaram submetidos à ação do frio durante 30 minutos. A tempreatura do banho de reaquecimento variou entre 36 e $40^{\circ}$, mas em quasi tôdas as experiências foi de $37^{\circ}$.

Quando colocados no banho frio, os sapos conservam a motilidade voluntária ainda por 5 a 6 minutos e em seguida caem em estado de anestesia.

Passados bruscamente para o banho quente, em um ou outro caso, alguns segundos após começam as contrações clonicas, principalmente dos musculos dos flancos. De um modo geral, porém, o ataque começa de meio minuto a minuto e meio após o início do reaquecimento. As contrações abrangem regiões cada vez mais largas, os membros entram em convulsões clonicas, assim como o assoalho da boca. Depois de algum tempo as contrações são tonico-clonícas e o animal toma atitudes forçadas com flexão do dorso.

A duração do ataque é variável. Breve em alguns casos, em outros é longa, podendo ir até dois minutos e meio. Em dado momento, entretanto, o animal desperta e começa a apresentar movimentos de natação. Retirado então do banho quente é verificada sua temperatura central por um termômetro introduzido no esofago e no estomago. Essa temperatura se encontra, como no caso das rãs, nas proximidades de $20^{\circ}$, o mais das vezes uma temperatura inferior à dos animais deixados na atmosfera do laboratório. Verifica-se assim que a reação observada para o lado do sistema nervoso não é devida à alta temperatura, mas tão sòmente à variação brusca de uma temperatura baixa para outra mais alta.

Depois de despertados, os animais continuam durante algum tempo com reações anormais. Os movimentos voluntários, os movimentos reflexos fazem-se com caráter rítmico, sendo os membros sede de abalos clonicos. Em alguns casos, é possível dizer que o animal tem ainda 
convulsões já depois de manifestações nítidas e claras de uma volta ao estado normal quanto às funções cerebrais.

A intensidade do ataque é variável com os indivíduos. Em sete experiências, uma foi negativa: não houve pròpriamente ataque, apenas uma ou outra contração breve dos membros. Entretanto, dos sapos examinados, nenhum apresentou ataque tão forte e tão violento como os que habitualmente são observados nas rãs. Nota-se também que o rítmo dos abalos é mais lento nos sapos do que no Leptodactylus ocellatus.

Lacertilios. 1. Tupinambis teguixin. Tivemos à nossa disposição, durante o período de nossas experiências, apenas dois exemplares dêsses Lagartos. Um dêles chegou ao laboratório bastante deprimido, o outro em muito boas condições para as experiências. Era um animal bastante grande, medindo 29,5 centímetros da ponta do nariz à raiz da cauda, tendo esta 66 centímetros de comprimento. Comprimento total do animal: 95,5 centímetros. A frequência respiratória normal, à temperatura do laboratório era de 16 movimentos por minuto.

17 de Janeiro de 1950. As 15h-17' - Posto no banho frio a $1 .^{\circ}, 5$. Teve fortes reações contra o frio, debatendo-se e procurando escapar. Foi mantido debaixo d'água e cercado de pedras de gêlo, ficando entretanto a extremidade do focinho acima do nível superior do líquido, para que pudesse respirar.

As 15 h. 35', os reflexos corneanos estavam presentes ainda, mas pouco depois não havia mais reação alguma. Fecharam-se os olhos, os movimentos respiratórios desapareceram e o animal ficou de todo inerte.

As 16 h. 7', isto é, 50 minutos após a imersão no banho frio, foi posto no banho quente a $40^{\circ}, 5$.

Dois minutos depois, primeiros movimentos da extremidade da cauda, que apresentava oscilações e contrações tonicas.

16 h. 11'. Primeiros movimentos clonicos dos dedos das patas posteriores. Os movimentos da cauda tornam-se mais acentuados $\mathrm{e}$ estendem-se na direção da raiz da mesma.

16 h. 13'. Movimentos de conjunto do tronco com caráter pendular, tornando-se mais intensas as contrações clonicas.

16 h. 14'. Extensão dos movimentos clonicos às patas anteriores. Logo depois os movimentos atingem a cabeça. Durante 3 minutos apresenta convulsões generalizadas, mantendo também sempre os movimentos pendulares do tronco. Continua em apnea e nenhum dos movimentos tem caracteres próprios da motilidade voluntária.

Às 16 h. 17', retirado do banho. Animal inerte.

Às 16 h. 18', os reflexos das patas, quando provocados são acompanhados de contrações clonicas das mesmas.

As 16 h. 21', os reflexos das patas retomam o caráter normal; recomeçam os movimentos respiratórios e o animal desperta.

As 16 h. 23', voltam os reflexos corneanos. Temp. rectal: $25^{\circ} 4$. 
As 16 h. 29', frequência respiratoria: 46 .

As 16 h. 30', ensaia os primeiros passos. Recupera a posição normal, quando dela é desviado. Apresenta, porém, franca incoordenação dos movimentos dos membros anteriores.

16 h. 36', frequência respiratória: 15. Volta à aparência normal.

Ao dia seguinte, 18 de Janeiro, foi submetido a nova experiência. Foi observada uma sequência semelhante de reações, mas estas já com intensidade bem mais reduzida que na primeira experiência.

Em uma terceira experiência sôbre o mesmo animal feita no dia 19, já não foi produzido um ataque pròpriamente dito. Os fenomenos convulsivos expontaneos ficaram quasi exclusivamente limitados à cauda. Os reflexos das patas, quando provocados por excitações mecânicas, faziam-se com caráter clonico acentuado. $O$ animal voltou, após a experiência, a apresentar uma aparência normal, mas, ao dia seguinte, 20 de Janeiro, foi encontrado morto.

O outro lagarto que, desde o início, se mostrava muito menos vivaz, não apresentou pròpriamente um ataque pelo reaquecimento. As reações eram limitadas à cauda, nada fortes. Os membros só reagiam quando excitados, sendo essas reações rítmicas, clonicas.

Em resumo, de dois lagartos grandes (T. teguixin) estudados, um apresentou ataque de reaquecimento, intenso, forte, revelando em sua evolução no tempo, caracteres especiais e interessantes. $O$ início do ataque na extremidade da cauda e a sua generalização ascendente é fenomeno que merece ser mais detidamente estudado.

2 Tropidurus torquatus. - Estes lagartos são de dimensões muito menores que os da espécie anterior. Têm de 10 a 20 centímetros de comprimento total. Tivemos à nossa disposição 7 exemplares .

Em 5 dos animais estudados, o reaquecimento brusco nada produziu de especial. Inertes, quando saiam do banho frio, permaneciam no banho quente sem nenhuma reação apreciável. Alguns, quando retirados do banho quente, continuavam inertes. Aberto o torax foi verificado que o coração pulsava. Outros readquiriram sua atividade normal após a ação das variações de temperatura, ficando no laboratório muitos dias ainda antes de serem libertados.

Apenas um dos exemplares estudados teve alguma coisa que merecesse o nome de ataque. Permaneceu no banho frio apenas 7 minutos e, posto no banho a $36^{\circ}$, apresentou 30 segundos após convulsões da cauda e dos membros sendo as primeiras mais acentuadas. Voltou depois à normal.

Outro não teve ataque só pela ação do reaquecimento, mas quando mecânicamente excitado com um bastão de vidro, apresentava descargas clonicas generalizadas, seguidas de atitude tonica em flexão do tronco, da cauda, formando uma espécie de arco, as patas fortemente apoiadas sôbre o tronco.

Em tôdas essas experiências, parece ter o tempo de resfriamento prévio do animal, grande importância. Nas experiências negativas, os 
valores dêsse tempo foram de $38,15,8,7,5$ minutos. Na experiência positiva, de 7 minutos; naquela em que houve reações clonicas, $8 \mathrm{mi}$ nutos.

Parece assim que, sendo possível o ataque, como o mostram uma experiência positiva e outra com o caráter acentuadamente clonico dos reflexos, faz-se êle em condições que é necessário bem determinar em trabalhos futuros.

\section{CONCLUSÕES}

1. O ataque pelo reaquecimento, observado até agora em gráo máximo, nas rãs sul-americanas do Rio de Janeiro. (L. ocellatus), apresenta-se muito aproximadamente com os mesmos caracteres e nas mesmas condições nos Sapos (B. crucifer). E' entretanto menos forte e de rítmo menos frequente.

2. O ataque pode ser obtido com caracteres especiais nos grandes lagartos (T. teguixin).

3 . Os pequenos lagartos ( $T$. torquatus) podem ter o ataque muito mais dificilmente e em condições que necessitam ser mais longamente estudadas. 